Original article

\title{
Awareness and perceptions of clinical guidelines for the diagnostics and treatment of severe behavioural problems in children across Europe: A qualitative survey with academic experts
}

\author{
Alexandra-Raluca Gatej ${ }^{\mathrm{a}, *}$, Audri Lamers ${ }^{\mathrm{a}, \mathrm{b}}$, Lieke van Domburgh ${ }^{\mathrm{c}, \mathrm{d}}$, Matty Crone , $^{\mathrm{e}}$ \\ Terje Ogden ${ }^{\mathrm{f}}$, Daniel Rijo ${ }^{\mathrm{g}}$, Eeva Aronen ${ }^{\mathrm{h}}$, Ricardo Barroso ${ }^{\mathrm{i}}$, Dorret I. Boomsma ${ }^{\mathrm{j}}$, \\ Robert Vermeiren ${ }^{\mathrm{a}, \mathrm{k}}$ \\ a Curium-LUMC, Academic Centre of Child and Youth Psychiatry, Endegeesterstraatweg 27, 2342 AK Oegstgeest, the Netherlands \\ ${ }^{\mathrm{b}}$ De Opvoedpoli, Child and Youth Psychiatry, Rode Kruisstraat 32, $1025 \mathrm{KN}$, Amsterdam, the Netherlands \\ ${ }^{\mathrm{c}}$ VU University Medical Centre, Department of Child and Adolescent Psychiatry, $1007 \mathrm{MB}$, Amsterdam, the Netherlands \\ d Intermetzo/Pluryn, Research and Development Department, PO Box 53, 6500 AB, Nijmegen, the Netherlands \\ ${ }^{\text {e }}$ Leiden University Medical Center (LUMC), Department of Public Health and Primary Care, Hippocratespad 21, 2333 ZD, Leiden, the Netherlands \\ ${ }^{\mathrm{f}}$ University of Oslo, Norwegian Center for Child Behavioral Development, PO Box 7053 Majorstuen, 0306, Oslo, Norway \\ g University of Coimbra, Faculty of Psychology and Education Sciences - CINEICC, Rua do Colégio Novo, 3000-115, Coimbra, Portugal \\ h University of Helsinki and Helsinki University Hospital, Children' Hospital, Child Psychiatry, Lastenlinnantie 2, 00250, Helsinki, Finland \\ ${ }^{\mathrm{i}}$ University of Trás-os-Montes and Alto Douro, Department of Education and Psychology, Pólo I - ECHS 5000-801, Vila Real, Portugal \\ ${ }^{\mathrm{j}} \mathrm{VU}$ University of Amsterdam, Department of Biological Psychology, Van der Boechorststraat 1, room 2B-29, 1081 BT, Amsterdam, the Netherlands \\ ${ }^{\mathrm{k}}$ Lucertis - de Jutters, Child and Adolescent Psychiatry, Parnassia Group, the Netherlands
}

\section{A R T I C L E I N F O}

\section{Article history:}

Received 7 October 2018

Received in revised form 28 December 2018

Accepted 29 December 2018

Available online 15 January 2019

\section{Keywords:}

Conduct disorder

Attention deficit - hyperactivity disorder

(ADHD)

Violence

Psychiatry in Europe

Psychometry and assessments in psychiatry

Epidemiology

\begin{abstract}
A B S T R A C T
Background: Severe behavioural problems $\left(\mathrm{SBPs}^{1}\right)$ in childhood are highly prevalent, impair functioning, and predict negative outcomes later in life. Over the last decade, clinical practice guidelines for SBPs have been developed across Europe to facilitate the translation of scientific evidence into clinical practice. This study outlines the results of an investigation into academic experts' perspectives on the current prevalence, implementation, and utility of clinical guidelines for SBPs in children aged 6-12 across Europe.

Methods: An online semi-structured questionnaire was completed by 28 psychiatry and psychology experts from 23 countries.

Results: Experts indicated that approximately two thirds of the included European countries use at least an unofficial clinical document such as textbooks, while nearly half possess official guidelines for SBPs. Experts believed that, although useful for practice, guidelines' benefits would be maximised if they included more specific recommendations and were implemented more conscientiously. Similarly, experts suggested that unofficial clinical documents offer a wide range of treatment options to individualise treatment from. However, they stressed the need for more consistent, evidence-based clinical practices, by means of developing national and European clinical guidelines for SBPs.

Conclusions: This study offers a preliminary insight into the current successes and challenges perceived by experts around Europe associated with guidelines and documents for SBPs, acting as a stepping stone for future systematic, in-depth investigations of guidelines. Additionally, it establishes experts' consensus for the need to develop official guidelines better tailored to clinical practice, creating a momentum for a transition towards European clinical guidelines for this population.
\end{abstract}

(C) 2019 The Authors. Published by Elsevier Masson SAS. This is an open access article under the CC BY-NCND license (http://creativecommons.org/licenses/by-nc-nd/4.0/).

\footnotetext{
* Corresponding author.

E-mail addresses: alexandraralucagatej@gmail.com, A.R.Gatej@curium.nl (A.-R. Gatej).

1 Severe behavioural problems (SBPs) were defined in this study as persistent and frequent oppositional, aggressive, and destructive behaviours (ie. severe aggression,

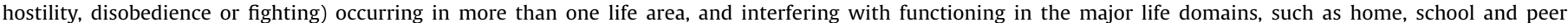

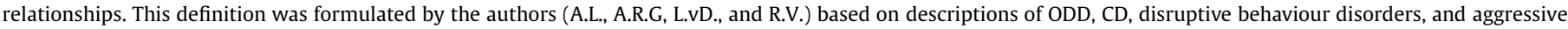

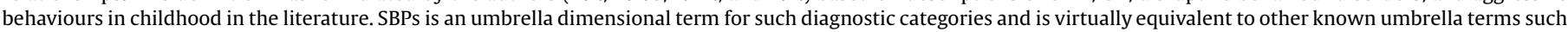
as 'disruptive behaviour disorders'.
} 


\section{Introduction}

A strong emphasis has recently been put on mental health practitioners incorporating evidence in their clinical decisionmaking [1,2]. However, this process is challenged by practitioners' limited resources to keep up to date with advances in research and the complex presentations of mental health issues encountered in clinical practice. Severe behavioural problems (SBPs) in children could be particularly challenging in this respect, as their clinical manifestation varies drastically between individuals. Consequently, over the years, clinical practice guidelines for diagnosing and treating SBPs in children have been developed in several European countries [3]. The scope of these guidelines is to support practitioners in taking evidence-based clinical decisions to maximise the effectiveness of treatment allocation and treatment outcomes [4]. Yet, a summary of the prevalence and views of these clinical guidelines for SBPs in children around Europe is missing. Developing such a European knowledge base could stimulate national and international collaboration within mental health services and across multi-disciplinary services, which often provide care to children with SBPs [5]. Additionally, a European knowledge base provides insight into which elements facilitate the implementation of guidelines and how guidelines could be better tailored to clinical practice. Consequently, this paper aimed to offer a first insight on the availability, perceived value and critical needs of clinical guidelines for SBPs in children across Europe, according to academic experts' perceptions.

SBPs in children are highly prevalent [6] and predict negative costly outcomes later in life [7,8]. Moreover, they are associated with alarming rates of poor response to or dropout from treatment $[9,10]$. SBPs in children can be described within the framework of diagnostic categories such as Oppositional Defiant Disorder (ODD) and Conduct Disorder (CD) $[11,12]$. However, their conceptualisation varies across Europe, as does the diagnostic classification system used [13]. Moreover, there has been an increasing drive in transitioning from categorical diagnoses towards a more dimensional bio-psycho-social case formulation [14,15]. To allow for a degree of applicability to each country's national standards, policies and conceptualization of behavioural problems, whilst still preserving uniformity in guidelines referred to, using the broader SBPs term was deemed appropriate. Hence, SBPs in childhood (6-12 years old) were defined as persistent, frequent, and impairing oppositional, defiant, and aggressive behaviours, occurring across several settings, and placed at the severe end of the behavioural disorders spectrum $[6,7,16]$. The term is virtually equivalent with previously used umbrella terms such as 'disruptive behaviour disorders/ problems' [e.g., 17-19].

Efforts to improve clinical practices for SBPs in children were marked by the development of official clinical guidelines on SBPs in several European countries. According to the Institute of Medicine [19], these guidelines were created based on recent systematic reviews and comprise of empirically-supported strategies for assessing and treating SBPs. Consensus amongst multidisciplinary clinical and academic experts accompanies these reviews. Theoretically, consensus indicates that guidelines would accelerate dissemination and incorporation of the most up-to-date scientific evidence into everyday clinical practice [20]. This in turn could reduce inappropriate practice variation [21] and improve coordination of care across involved agencies and choice of efficacious interventions. However, concerns have also been expressed that guidelines provide an oversimplified "cook book" approach to address complex clinical questions [19]. Additionally, they may restrict clinicians' autonomy in customising interventions to individual patients, local resources, or cultural values $[20,22]$. The question that arises is whether such clinical guidelines for children with SBPs are available across different European countries and, when available, whether they are perceived as fitfor-purpose.

This study aimed to compile a preliminary summary of European academic experts' reflections on the availability, contribution of and need for developing guidelines for the diagnostics and treatment of SBPs in children. Knowledge on additional unofficial documents on SBPs, such as textbooks, publications, or intervention manuals was also collected. In Europe, many experts are involved in guidelines planning and evaluation (e.g., [23]). Collecting experts' opinions would provide the beginning of further systematically conducted, in-depth analyses of guidelines implementation between and within countries, and help identify current facilitators and barriers to implementing evidence into practice to proffer educated solutions.

\section{Method}

\subsection{Recruitment and participants}

The Knowledge Centre of Child and Adolescent Psychiatry in The Netherlands was first approached to locate experts in SBPs within the Netherlands. Moreover, the authors (A.R.G., A.L., L.vD., and R.V.) screened for members of European child and adolescent mental health organisations, such as the European Society of Child and Adolescent Psychiatry, the European Association for Forensic Child \& Adolescent Psychiatry, Psychology \& other Involved Professions, and Consortium Aggression in Children: Unravelling gene-environment interplay to inform Treatment and InterventiON strategies (ACTION). Lastly, the authors screened peer-reviewed scientific publications on ODD or CD for recurrent authors. These publications were retrieved based on search terms such as: "childhood aggression", "disruptive behaviour disorders", or "conduct disorder" on PsycInfo, Medline and Embase platforms and evidence-based programs websites such as Incredible Years [24] and Triple P [25]. Given that no exhaustive list of experts in SBPs was available, screening literature and case snowball sampling were used based on previous Delphi expert panel studies [26-29].

Expertise was also established based on previously employed criteria [e.g., conference presentations, articles/ books authorships; [25-28]. Therefore, at screening stage, potential experts were included if they met either of the minimum criteria: lead authorship of national/international publications on SBPs; research on or involvement in evidence-based programs for SBPs; participation in guidelines development for SBPs; or recommendation from academic colleagues. This was followed by further investigation of potential experts' research profiles on institutional/ professional websites, publication history and involvement in national bodies, all of which had to target SBPs as a primary field. Corroborating these criteria led to an estimate of one's expertise. To account for financial and language barriers that may have prevented experts from lower developed countries to be identified, such experts were invited if at least one of the criteria above was met. Once invited, all experts were able to express whether they felt sufficiently knowledgeable to participate or recommended a suitable colleague. Altogether, 72 experts from 28 European countries were invited. Responses were received from 28 experts (38.9\%) representing 23 countries, with both medical (50\%) and psychology (50\%) educational backgrounds and an array of professional roles and experiences. This diversity in the expert group has been deemed valuable in similar expert panel studies [27]. Of the 44 experts that did not provide answers, seven felt unsuitable to participate and recommended colleagues. Respondents' and non-respondents' professional roles are presented in Tables 1-2. 
Table 1

Respondents: Academic Experts - Current roles and background.

\begin{tabular}{|c|c|}
\hline Current Position/Title & Experts \\
\hline Full/Associate Professors (child and adolescent psychiatry/ psychopathology/ education) & $22(78.6 \%)$ \\
\hline (Child and Adolescent) Psychiatrists & $9(32.1 \%)$ \\
\hline Directors/ Head of Departments (child \& adolescent psychiatric clinic, human development) & $9(32.1 \%)$ \\
\hline Child and Adolescent (Clinical) Psychologists & $4(14.3 \%)$ \\
\hline Research-predominance in Clinics/Institutes & $4(14.3 \%)$ \\
\hline Senior Mental Health Advisors (e.g., in government-led institutions, ministry of health; associations of psychiatrists) & $4(14.3 \%)$ \\
\hline National/ European Guidelines Development Group Contributors & $3(10.7 \%)$ \\
\hline
\end{tabular}

Note. Some academics have more than one title and have been endorsed under all relevant categories.. Titles and positions have been retrieved through online manual searches and may not be exhaustive of experts' current roles. Percentages were calculated out of the total number of experts, $N=28$.

Table 2

Non-respondents: Academic Experts - Current roles and background.

\begin{tabular}{|c|c|}
\hline Current Position/Title & Experts \\
\hline Full/Associate Professors (child and adolescent psychiatry/ psychopathology/ education) & $26(59.1 \%)$ \\
\hline (Child and Adolescent) Psychiatrists & $13(29.5 \%)$ \\
\hline Directors/ Head of Departments (child \& adolescent psychiatric clinic, human development) & $12(27.3 \%)$ \\
\hline Child and Adolescent (Clinical) Psychologists & $3(6.8 \%)$ \\
\hline Research-predominance in Clinics/Institutes & $7(15.9 \%)$ \\
\hline Senior Mental Health Advisors (e.g., in government-led institutions, ministry of health; associations of psychiatrists) & $4(9.1 \%)$ \\
\hline National/ European Guidelines Development Group Contributors & $2(4.5 \%)$ \\
\hline Psychologist - Other (e.g., forensic) & $5(11.4 \%)$ \\
\hline
\end{tabular}

Note. Some academics have more than one title and have been endorsed under all relevant categories. Titles and positions have been retrieved through online manual searches and may not be exhaustive of experts' current roles. Percentages were calculated out of the total number of non-respondent experts, $n=44$.

\subsection{Instruments}

An electronic semi-structured questionnaire was developed for this study. The questionnaire included a definition of SBPs and 12 questions. SBPs in childhood(6-12 years old), placed at the severe end of the behavioural disorders continuum, were defined as persistent and frequent oppositional, aggressive, and destructive behaviours, occurring across settings, and interfering with daily functioning. This definition was formulated by the authors (A.L., A.R.G, L.vD., and R.V.) based on descriptions of ODD, CD, and disruptive behaviour disorders in childhood in the literature (e.g. [6,9]). The questionnaire was compiled by A.L. and A.R.G., with feedback from three other authors (M.C., L.vD., and R.V.), and reviews from three experts in qualitative research. The questionnaire was piloted on five experts from different European countries. Their responses reflected good understanding of the questions, indicating that the questionnaire explored what it was intended to. The first topic covered explored the availability, utility, and critical needs of official guidelines and/or unofficial documents for diagnosing and treating SBPs in children. The second topic covered the need for developing such national and/or European guidelines. The questionnaire is available upon request.

\subsection{Procedure}

Responses were collected on the online platform Qualtrics. Experts were invited to participate via a personalised email, followed by three weekly email reminders, and a final reminder sent via the person who recommended the expert, where available. Lastly, a member check was conducted, in which experts checked whether their opinion/country was correctly represented in a written report summarising the answers. This quality control process was performed to ensure that responses were accurately analysed [cf., 30], and that experts' answers in each country were accurately represented. Of the 28 experts, 22 provided feedback on the report within a two-week timeframe. All minor corrections resulting from the member check were carried out and the final outcomes are further reported. The data collection process was guided by a Delphi procedure [27], although it differed from a Delphi study by being explorative rather than seeking to establish consensus. Data collection was conducted over a period of eight months.

\subsection{Data analysis}

Definitions of guidelines/ documents were developed following data collection. Official clinical guidelines included a systematic, evidence-based set of recommendations for the diagnostics and treatment of SBPs in children, that were created following collective efforts from academic experts, clinicians, and relevant institutions. Unofficial clinical documents were regarded as textbooks, chapters, publications, intervention manuals, or practice parameters on externalising disorders, containing guidance on either diagnostics or treatment or both for SBPs in children. The authors used these definitions to categorise the documents mentioned by experts into the corresponding group. For broader open-ended questions, extraction of themes was done in line with thematic analysis steps. These involved familiarization with the data, generating initial codes, and identifying, reviewing, and defining themes [31,32]. Due to the very brief answers offered by experts, the analysis was limited to identifying semantic, surface meanings, rather than rich latent-level conceptualisations [32]. To organise information into multilevel lists, numerical codes were annexed to themes and sub-themes, in line with previous studies [26,33]. For instance, Huijg et al. [33] coded the domain 'Emotion' as 'D13' out of the 14 domains studied, under which two subordinate constructs were coded: Affect, and Stress. Similarly, we coded themes such as 'familiarity with guidelines' as ' 1 ', with sub-themes as: '1.1. little familiarity', '1.2. average familiarity', and '1.3. good familiarity'. Two authors have independently reviewed and coded $25 \%$ of the data (A.L., and A.R.G.). A 95\% agreement was achieved for the highest-level broader codes/themes in the openended questions (e.g., professionals using guidelines), and categorical questions (e.g., 'are guidelines available?'). Divergences emerging at sub-themes levels were fully resolved by reviewing the constructs through a telephone meeting. All responses were exhaustively represented under the final themes. Frequencies with which a theme/sub-theme was mentioned were also reported. To 
assess for saturation of data, we used the inductive thematic approach by which saturation occurred when no novel codes/ themes emerged in data analysis [34,35]. Data closely approached thematic saturation on discussing the need for developing, or utility and critical needs for guidelines. Lack of saturation on questions such as the utility and critical needs for unofficial documents may have reflected an artefact of the great variety in unofficial documents referred to by clinicians. Overall, adding that previous Delphi studies using expert panels also identified that data gets saturated in expert panels that exceed thirty participants, number which we nearly reached [29], we were confident that some of our material reached saturation.

\section{Results}

\subsection{Official clinical guidelines}

\subsubsection{Status}

According to experts' knowledge ( $N=28$ from 23 countries), 10 out of 23 countries possessed official guidelines for SBPs in children (43.5\%), and Finland intended to publish national guidelines for conduct disorder in December 2018 (Fig.1). Most guidelines were developed by a group of experts within the national public health services/directorate or national child psychiatry associations. Overall, child psychiatrists were the professionals most frequently mentioned as drawing on these official clinical guidelines to inform practices across Europe ( $n=7$ countries), followed by psychologists ( $n=6$ countries), teachers ( $n=4$ countries), social services ( $n=2$ countries) and paediatricians ( $n=1$ country). Professionals' familiarity with guidelines ranged from guidelines being generally ignored, to "almost all (those employed in the official mental health service) being familiar with these (guidelines) and should abide them." (expert opinion).

\subsubsection{Utility and critical needs}

The content of clinical guidelines was perceived as helpful in daily practice by experts in six out of the ten countries currently having such guidelines: "It is a good reference for everyday work. The professional feels safer because s/he knows what do to for each disorder with guarantee of choosing a good intervention (evidence-based)." However, experts identified the following critical needs that should be addressed to improve existing guidelines. Content related adjustments included adding specific recommendations for individual case management, including recommendations for severely aggressive patients (e.g., de-escalation strategies in hospitals) $(n=2)$ and incorporating forensic perspectives such as offence orientated psychotherapy $(n=2)$. Implementation efforts consisted of collecting feedback from practitioners to better tailor recommendations to clinical practice $(n=1)$, persuading commissioners to prioritise SBPs $(n=1)$, and training staff in recommended evidence-based methods (EBMs), including parent training and cognitive behavioural therapy-based programs $(n=1)$.

\subsection{Unofficial clinical documents}

\subsubsection{Status}

Experts in 14 out of the 23 countries indicated that unofficial clinical documents were available (60.9\%). In seven of these countries these unofficial documents were used alongside official guidelines (Fig. 1). These included clinical reports, manuals or psychiatry textbooks on ODD/CD in children $(n=12)$, national and/ or international practice parameters for CD $(n=1)$, and governmental sponsored recommendations respectively (e.g., The Incredible Years, [24] etc.; $n=1$ ). According to the experts' knowledge, psychiatrists ( $n=13$ countries) and psychologists ( $n=12$ countries) were the professionals who used these documents most actively across Europe, followed by teachers
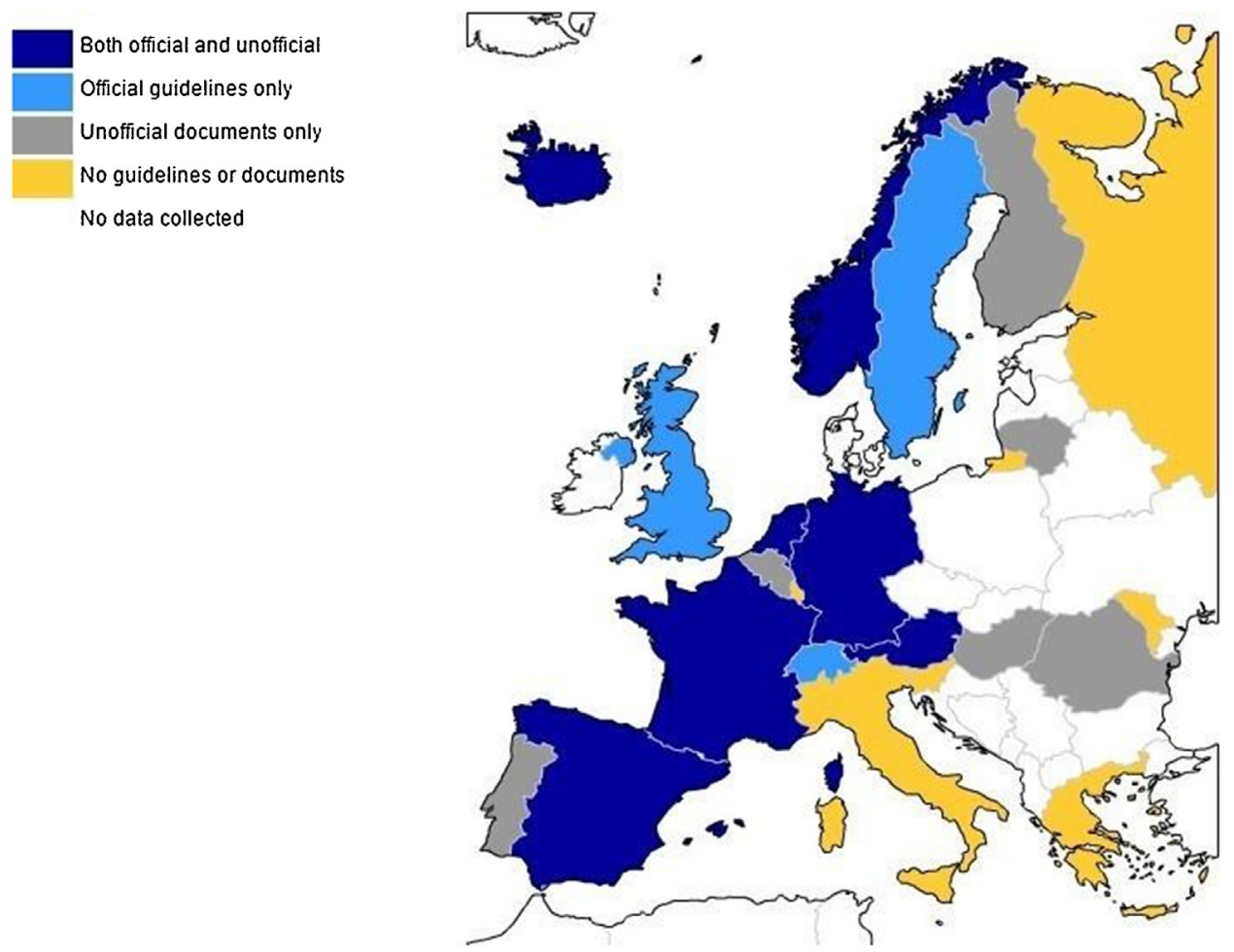

Fig. 1. Status of official clinical guidelines and unofficial clinical documents for SBPs in children.

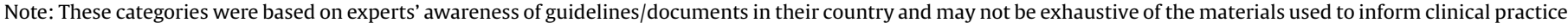

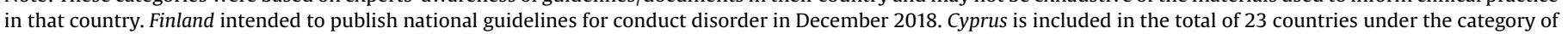
Unofficial documents only. All blank spaces indicate countries were no data was collected. 
( $n=2$ countries), social/child protection services ( $n=2$ countries), psychotherapists ( $n=2$ countries), and general practitioners $(n=1$ country). Their familiarity with these documents varied from little (e.g., 'Far from all know about them and use them. I Think many need more training to be able to apply them.') to good familiarity across countries (e.g., 'These official, but not mandatory, suggestions are widely followed by psychiatrists, psychologists and social workers alike') based on experts' views.

\subsubsection{Utility and critical needs}

Unofficial clinical documents were perceived as helpful in guiding clinical practice by experts in three countries. On the one hand, maximising the practical value of these documents were content components such as EBM recommendations $(n=1)$ and/or behavioural management models $(n=1)$, and implementation aspects such as support from (governmental) health authorities via staff training $(n=1)$, or offering a wide range of treatment recommendations and approaches to support personalising interventions $(n=1)$. On the other hand, experts identified several problems underlying the content and use of such documents in clinical practice. At content level, they lacked cohesiveness and breadth of approaches $(n=4)$ or evidence-based interventions $(n=1)$. Implementation challenges included limitations over the resources for assessment and treatment $(n=2)$ and translated resources $(n=1)$ available in practice to apply documents recommendations, inconsistent application of tools between practitioners $(n=2)$, practitioners' limited knowledge about existing recommendations $(n=1)$, and the format of such documents being hard to translate in practice $(n=1)$. Critical needs included developing a clear, specific, and practical clinical guideline for SBPs $(n=7)$ accompanied by a dissemination program $(n=1)$, improving measures for existing EBM resources and more randomized-control trials on medication effectiveness $(n=1)$.

\subsection{Need for national and/or european clinical guidelines for SBPS}

Of the experts reporting on whether national guidelines for SBPs in children are needed ( $n=27$ from 22 countries), at least one expert was in favour of developing such guidelines in 16 countries ( $n=18,66.7 \%)$. Of the experts reporting on whether European guidelines for SBPs in children are needed $(n=25$ from 21 countries), at least one expert was in favour of developing such guidelines in 19 countries $(n=21,84 \%)$. Themes emerging on the benefits and drawbacks of developing such guidelines are presented in Table 3.

\section{Discussion}

This study provides a first insight into the availability and utility of clinical guidelines for SBPs in children across Europe, based on academic experts' knowledge. Experts indicated that official guidelines and unofficial documents were available in nearly half and two thirds of countries respectively. Two key lessons offered by experts are highlighted. First, official clinical guidelines for SBPs are regarded as beneficial, but their implementation needs to be reinforced and content better tailored to daily practice. Second, having a diverse pool of recommendations is beneficial in individualising treatment. However, attention is directed towards a better standardisation of practices, through the collaborative creation of national and/or European clinical guidelines for SBPs.

First, our findings indicate that guidelines provide support for evidence-based clinical decisions. A salient challenge is clinicians

Table 3

Benefits and drawbacks on developing national and/or European guidelines for SBPs.

\begin{tabular}{|c|c|c|c|c|}
\hline Theme & Sub-themes & $\begin{array}{l}\mathrm{n} \\
\text { (National) }\end{array}$ & $\begin{array}{l}\mathrm{n} \\
\text { (European) }\end{array}$ & Quote \\
\hline \multirow[t]{6}{*}{ Benefits } & $\begin{array}{l}\text { Improve early intervention and } \\
\text { prevention }\end{array}$ & $\mathrm{n}=3$ & $\mathrm{n}=1$ & $\begin{array}{l}\text { "It would allow professionals to sustain early identification of disturbed children; it } \\
\text { would stress the need for early and specific interventions and it would help to develop } \\
\text { appropriate treatment approaches from the mental health services" }\end{array}$ \\
\hline & Encourage implementation of EBMs & $\mathrm{n}=3$ & $\mathrm{n}=7$ & $\begin{array}{l}\text { "Commonly professionals use best practices for diagnosis and treatment, however in the } \\
\text { field of primary prevention it is rarer that professionals use good practices. In general, } \\
\text { there is not enough emphasis on evidence-based interventions." }\end{array}$ \\
\hline & $\begin{array}{l}\text { Increase consistency in practice } \\
\text { (within and between countries) }\end{array}$ & $\mathrm{n}=3$ & $\mathrm{n}=5$ & $\begin{array}{l}\text { "would harmonize the clinical practice and use the most relevant methods/interventions, } \\
\text { so that children could benefit from the highest available clinical care" }\end{array}$ \\
\hline & Increase accessibility of services & $\mathrm{n}=2$ & $\mathrm{n}=1$ & $\begin{array}{l}\text { "in order to secure that all eligible children are offered treatment adapted to their needs. } \\
\text { Some of the high need children (particularly immigrant children and children in child } \\
\text { welfare services) are not being reached" }\end{array}$ \\
\hline & $\begin{array}{l}\text { Promote a shared framework for } \\
\text { understanding SBPs and negotiation }\end{array}$ & $\mathrm{n}=1$ & $\mathrm{n}=4$ & $\begin{array}{l}\text { "(Guidelines) could provide a general framework that will be used for further research } \\
\text { programs on prevention of SBPs. The lack of consensus regarding the definitions of SBPs } \\
\text { (in particular, how it could be distinguished from a normal developmental period in } \\
\text { childhood) is confusing for clinicians" }\end{array}$ \\
\hline & $\begin{array}{l}\text { Support further national guidelines } \\
\text { development }\end{array}$ & $\mathrm{n}=0$ & $\mathrm{n}=6$ & $\begin{array}{l}\text { "European guidelines will be helpful, in particular for smaller countries or countries with } \\
\text { a lower standard of care that do not have the resources to develop such guidelines in their } \\
\text { own right" }\end{array}$ \\
\hline \multirow[t]{7}{*}{ Challenges } & Lack of resources: & $\mathrm{n}=1$ & $\mathrm{n}=0$ & "I do not believe that X is big enough to establish own evidence-based guidelines, as we \\
\hline & $\begin{array}{l}\text { Sub-theme 1: small countries lacking } \\
\text { critical mass } \\
\text { Sub-theme 2: lack of time and long } \\
\text { processes in updating policies }\end{array}$ & $\mathrm{n}=1$ & $\mathrm{n}=0$ & $\begin{array}{l}\text { do not have enough critical mass. More reasonable would be to adopt other guidelines } \\
\text { (German, European, International). The problem is, that you will need to do this } 26 \text { times, } \\
\text { what makes policy making in X a very cumbersome process" }\end{array}$ \\
\hline & $\begin{array}{l}\text { Guidelines are adequate but need } \\
\text { better implementation }\end{array}$ & $\mathrm{n}=2$ & $\mathrm{n}=2$ & $\begin{array}{l}\text { "What is needed is a publicity campaign to persuade people to use them, that serious } \\
\text { antisocial behaviour is a massive problem for both the individual and society, and that we } \\
\text { have a reasonable number of follow-up studies showing good long-term effects of early } \\
\text { intervention." }\end{array}$ \\
\hline & Need additional support: & $\mathrm{n}=1$ & $\mathrm{n}=0$ & "yes for sure [there is a need for guidelines] but also to train staff accordingly" \\
\hline & Sub-theme 1: staff training & $\mathrm{n}=1$ & $\mathrm{n}=0$ & "the implementation may be strengthened through legislation" \\
\hline & Sub-theme 2: governmental legislation & & & \\
\hline & $\begin{array}{l}\text { Accounting for the cultural, financial, } \\
\text { health, and legal systems differences }\end{array}$ & $\mathrm{n}=0$ & $\mathrm{n}=2$ & $\begin{array}{l}\text { "[European guidelines would be needed] if they will take into account realities of } \\
\text { different countries with very different financial and human resources available" }\end{array}$ \\
\hline
\end{tabular}


familiarising with and implementing them in practice. This issue reflects previous warnings that guidelines need to be accompanied by implementation tools such as instructions on overcoming barriers for their use in practice to be maximised [36,37]. Experts offered suggestions for improvement, including the incorporation of specific recommendations to reflect the diversity of cases in daily practice, training staff to increase familiarity with guidelines and EBMs implicitly, and persuading commissioners to prioritise SBPs. These mirror at a larger scale, critical needs in public mental health initiatives. For instance, a systematic meta-review identified that including recommendations for complex presentations within guidelines might facilitate translating population-based guidelines into individualized formulations and treatment plans [4], see also [16]. Additionally, insufficient training usually results in poor familiarity with guidelines [38], a factor consistently mentioned as a barrier to implementation [39-41]. Finally, senior government decision-makers on mental health, public health experts and academics internationally have stressed that mental health care deserves more attention [42], an aspect also highlighted with regards to SBPs by experts in this study.

The second lesson taught by experts is that a shift towards a comprehensive, shared pool of recommendations is needed to reduce the unwarranted practice variation that may arise with the use of unofficial clinical documents exclusively. The development of official national/ European clinical guidelines would answer this plea. $66.7 \%$ and $84 \%$ experts respectively called for the development and dissemination of national and European guidelines on SBPs in children, mirroring professional consensus on the topic in other fields [43] and recent developments of European guidelines for other paediatric mental health disorders [44]. National and European guidelines share three main benefits according to experts' opinions. They would encourage standardised clinical decision-making, create a shared understanding of SBPs for researchers and clinicians, and increase accessibility to EBMs and early intervention. These would address previous calls for increasing awareness of SBPs and early intervention [45]. However, experts emphasised the potentially superior value of European guidelines, although acknowledging the challenges social, health, and cultural differences between countries create. European guidelines were believed to support the development of a national guideline, answering calls for globalising the evidence while localising the recommendations [46]. Additionally, they could maximise harmony between clinical practices and stimulate negotiations amongst multi-disciplinary professionals both within and between countries [5].

Nevertheless, the study had several significant limitations. First, there was selection bias, as case snowball sampling and screening of literature primarily written in English were used. Despite being the best available and commonly employed method in this type of research $[26,28,29]$, this may have increased heterogeneity in experts' levels of knowledge and dismissed potentially suitable experts. Thus, the results present only preliminary subjective opinions, rather than a comprehensive objective inventory on guidelines across countries. These could inform future systematic or qualitative studies investigating information derived from a range of stakeholders sampled in a more systematic manner, such as practitioners rating their use of guidelines and perceptions of usefulness and need for change. Second, SBPs associated with other disorders (ie. ADHD, ASD, learning disability etc.) were not specifically excluded from the definition. Therefore, recommendations on SBPs management may have also been available in clinical guidelines for comorbid conditions or neurodevelopmental disorders, potentially increasing inconsistencies between what documents respondents reported about. Finally, we have not checked whether experts used high quality systematic evidence such as audits, governmental reports, or meta-analyses, or personal/ professional experience to inform judgments on guidelines, concerns highlighted in previous Delphi studies [e.g., 27]. This poses threats over the degree of accuracy and generalisability of the data. Future researchers should thus explicitly identify experts' data sources in the answers, or collect such reports themselves, using experts as facilitators in identifying the reports in the first place.

Overall, based on this study's findings, guidelines better adjusted to clinical practice should include a wide pool of EBMs, specific recommendations for different presentations (e.g., deescalation strategies for severely aggressive patients), and feedback from practitioners. Implementation efforts could encompass persuading commissioners to prioritise SBPs, training staff in recommended EBMs, securing national government/ health authorities support, formatting guidelines in a clinicallyfriendly, concise and clear way, translating recommendations, and providing adjacent dissemination instructions. Finally, the high comorbidity between SBPs and other neurodevelopmental or mental health disorders [47-49] stresses the importance of aligning SBP guidelines with guidelines for other overlapping disorders.

The present study has research, service and policy implications. First, experts stressed that guidelines would enhance clarity between research and clinical practice on SBPs. Second, implementation of guidelines should be improved. Third, having a consensus-based national or European framework for managing SBPs in children would strengthen incorporation of evidence in clinical-decision making, increase awareness, and thus early intervention for this group. This study instils a momentum for the creation of European clinical guidelines for this population.

\section{Declarations of interest}

The manuscript does not contain clinical studies or patient data. Declarations of interest: None.

\section{Acknowledgments}

Key experts in the field of SBPs in Europe who completed the questionnaire included: P.D. Dr. Belinda Plattner (Austria), Prof. Dr. Dirk van West (Belgium), Assoc. Prof. Kostas Fanti (Cyprus), Prof. Dr. Eeva Aronen (Finland), Prof. Dr. David Cohen (France), Prof. Dr. Christine Freitag (Germany), Prof. Dr. Christina Stadler (Germany), Assoc. Prof. Dr. Dimitris Anagnostopoulos (Greece), Dr.Margrét Sigmarsdóttir (Iceland), Dr. Pietro Muratori (Italy), Dr. Darius Leskaukas (Lithuania), Dr. Roland Paulauskas (Lithuania), Assoc. Prof. Jana Chihai (Repulic of Moldova), Prof. Emerit. Walter Matthys (Netherlands), Prof. Dr. Terje Ogden (Norway), Prof. Dr. Lars Wichstrom (Norway), Prof. Dr. Daniel Rijo (Portugal), Prof. Dr. Ricardo Barroso (Portugal), Assist. Prof. Dr. Elena Predescu (Romania), Assist. Prof. Maja Drobnic Radobuljac (Slovenia), Prof. Dr. Stephen Scott (UK). Experts in four countries wished not to be mentioned in publications resulting from this project. Experts in a remaining three countries did not indicate whether they wish to be mentioned. Additionally, experts in qualitative research and psychiatric research ethics who contributed to the creation, revision and analysis of the questionnaire included: Dr. Matty Crone, Prof. Dr. Catrin Finkenauer, Prof. Dr. Gerben Meynen, Prof. Dr. Ria Reis, Jeroen de Winter (Clin. Psy.), and Anne Hendriks (PhD Candidate). work was supported by ACTION (Aggression in Children: unravelling gene-environment interplay to inform Treatment and InterventiON strategies), funded under the European Union Seventh Framework Program (FP7/2007-2013) [grant number 602768]. 


\section{Appendix A. List of guidelines and unofficial documents referred to by experts}

See Tables A1 and A2.

Table A1

Clinical guidelines referred to by experts.

\begin{tabular}{|c|c|c|c|}
\hline Country & Guideline referred to & Development date & Developing body \\
\hline Austria & AMWF Leitlinien (www.awmf.org) & S1 - 2006 & $\begin{array}{l}\text { German Society of Child and } \\
\text { Adolescent Psychiatry (S1 - Prof. Dr. } \\
\text { Martin Schmidt) }\end{array}$ \\
\hline Germany & S1, S3 Störungend es Sozialverhaltens on ODD and CD (AWMF) (www.awmf.org) & $\begin{array}{l}\text { S1 }-2006 \\
\text { S3 }-2016\end{array}$ & $\begin{array}{l}\text { German Society of Child and } \\
\text { Adolescent Psychiatry (S1 - Prof. Dr. } \\
\text { Martin Schmidt \& Prof. Dr. Fritz } \\
\text { Poustka) }\end{array}$ \\
\hline Iceland & $\begin{array}{l}\text { ESTER: an assessment tool for social workers to choose relevant interventions (not } \\
\text { freely available; provided to professionals that have been trained to use the instrument) }\end{array}$ & Not reported & Swedish experts \\
\hline Netherlands & $\begin{array}{l}\text { Richtlijn oppositioneel-opstandige stoornis (ODD) en gedragsstoornis (CD) in kinderen } \\
\text { en jongeren (Guidelines for oppositional-defiant disorder/ ODD, and conduct disorder/ } \\
\text { CD in children and adolescents; purchasing from De Tijdstroom) }\end{array}$ & 2013 & $\begin{array}{l}\text { Prof. Dr. Walter Matthys and Dr. } \\
\text { Geurt van de Glind (Authors) }\end{array}$ \\
\hline Norway & $\begin{array}{l}\text { The Norwegian Directorate of Health's Guidelines for Child and Adolescent Outpatient } \\
\text { Clinics (https://helsedirektoratet.no/Lists/Publikasjoner/Attachments/252/Psykisk- } \\
\text { helsevern-for-barn-og-unge-veileder-for-poliklinikker-IS-1570.pdf) }\end{array}$ & 2008 & $\begin{array}{l}\text { The Norwegian Directorate of } \\
\text { Health }\end{array}$ \\
\hline Spain & $\begin{array}{l}\text { Guía didáctica trastornos del comportamiento - Gobierno de Canarias. Trastornos de la } \\
\text { conducta - Gobierno de Aragón (Teaching guudelines for behavioural disorders - Canary } \\
\text { Islands Government; Aragon Government; http://docplayer.es/7355537-Guia- } \\
\text { didactica-trastornos-del-comportamiento.html) }\end{array}$ & 2010 & $\begin{array}{l}\text { Servicio Canario de Salud (Canarian } \\
\text { Service of Health) }\end{array}$ \\
\hline Sweden & Stockholm child and adolescent psychiatry guidelines & Not reported & Not reported \\
\hline Switzerland & $\begin{array}{l}\text { German Guidelines of child and adolescent psychiatry; e.g. DGKJP AWMF 028-019, 028- } \\
036 \text { (www.awmf.org) }\end{array}$ & Not reported & $\begin{array}{l}\text { German Society of Child and } \\
\text { Adolescent Psychiatry }\end{array}$ \\
\hline UK & $\begin{array}{l}\text { Guideline on antisocial behaviours and conduct disorders (https://www.nice.org.uk/ } \\
\text { guidance/cg158) }\end{array}$ & 2013 & $\begin{array}{l}\text { NICE Guideline Development } \\
\text { Group }\end{array}$ \\
\hline
\end{tabular}

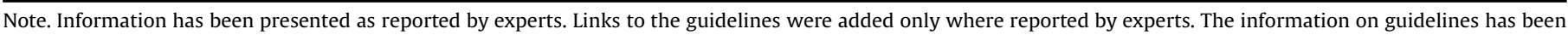
collected up to June 2016 and does not capture any new developments since.

Table A2

Unofficial documents referred to by experts.

\begin{tabular}{|c|c|c|c|}
\hline Country & Unofficial document referred to & Development date & Developing body \\
\hline Belgium & $\begin{array}{l}\text { Hoge Gezondheidsraad (HGR nr. 8325) (http://health.belgium.be/internet2Prd/groups/public/ } \\
\text { @public/@shc/documents/ie2dicivers/19072167.pdf) }\end{array}$ & March 2011 & Hoge Gezondheidsraad \\
\hline Cyprus & $\mathrm{CBCL}$ & Not reported & Not reported \\
\hline Finland & $\begin{array}{l}\text { Book chapter in textbook: Child and Adolescent Psychiatry (2016). Articles in Finnish Medical and } \\
\text { Psychology Journals (found in libraries, online) }\end{array}$ & 2016 & Not reported \\
\hline France & $\begin{array}{l}\text { Trouble des conduits chez l'enfant et l'adolescent (Conduct problems in children and adolescents; } \\
\text { www.inserm.fr/content/download/7154/ . . /troubles + des + conduites.pdf) }\end{array}$ & 2006 & Inserm \\
\hline Germany & $\begin{array}{l}\text { several books and treatment manuals; } \\
\text { reviews, book chapters (but not unofficial) and in line with guidelines }\end{array}$ & Not reported & Not reported \\
\hline Greece & ICD-10 & Not reported & WHO \\
\hline Hungary & $\begin{array}{l}\text { Handbook of child and adolescent psychiatry, English-language guidelines (textbooks available } \\
\text { for purchasing online; AACAP and NICE guidelines could also be used) }\end{array}$ & Not reported & $\begin{array}{l}\text { AACAP; NICE Guideline } \\
\text { Development Group }\end{array}$ \\
\hline Iceland & ICD-10 & Not reported & WHO \\
\hline Lithuania & $\begin{array}{l}\text { ICD-10; DSM-V; } \\
\text { Chapters in textbooks, recommendations for the treatment of ADHD recommended by the health } \\
\text { care ministry (textbooks available in libraries, recommendations on the Ministry's internet portal) }\end{array}$ & Not reported & $\begin{array}{l}\text { WHO; } \\
\text { APA; } \\
\text { Health Care Ministry }\end{array}$ \\
\hline Netherlands & $\begin{array}{l}\text { Textbook on child and adolescent psychiatry edited by F.C. Verhulst, F. Verheij \& Danckaerts } \\
\text { (2014); Textbook on psychopathology edited by I. Franken, P. Muris, \& D. Denys (2015): chapters } \\
\text { on ODD and CD.(purchasing at Koninklijke van Gorcum, de Tijdstroom) }\end{array}$ & $\begin{array}{l}2014 ; \\
2015\end{array}$ & $\begin{array}{l}\text { Walter Matthys, } \\
\text { Dirk van West }\end{array}$ \\
\hline Norway & $\begin{array}{l}\text { Governmental sponsored programs to treat SBPs: The Incredible Years (Webster-Stratton), Parent } \\
\text { Management Training - Oregon (PMTO), and Multisystemic Therapy (MST); For severe cases } \\
\text { within the Child Protection Services, MultifuncC;. Other recommendations from authorities: } \\
\text { Aggression Replacement Therapy (ART) and Functional Family Therapy (e.g., http://www.bufdir. } \\
\text { no/barnevern/Tiltak_i_barnevernet/Metoder/The Directorate of Children and Families) }\end{array}$ & Not reported & $\begin{array}{l}\text { The Directorate of } \\
\text { Children and Families; } \\
\text { Government }\end{array}$ \\
\hline Portugal & $\begin{array}{l}\text { Defiant Children: A Clinician's Manual for Assessment and Parent Training (not available for the } \\
\text { general population; some health services and charity institutions may upload the program } \\
\text { online) }\end{array}$ & 1997 & Russell Barkley \\
\hline Romania & $\begin{array}{l}\text { ICD 10; DSM IV and V; Practice Parameters (AACAP) for Conduct disorder and Atypical } \\
\text { Antipsychotic Medication; IACAPAP textbook of Child and Adolescent Mental Health (chapters } \\
\text { Oppositional Defiant Disorder and Conduct Disorder) (on IACAPAP or AACAP webpages) }\end{array}$ & Not reported & $\begin{array}{l}\text { WHO; APA; } \\
\text { IACAPAP } \\
\text { AACAP }\end{array}$ \\
\hline Spain & $\begin{array}{l}\text { Serrano, I. Videos sobre Entrenamiento de padres y maestros y Formacion de HH SS (Videos on } \\
\text { Parent and Teacher Training and Social Skills Training); } \\
\text { Translations of Russell Barkley's books on SBPs. Publications on ADH; publications in English. } \\
\text { (available on some websites of associations and charities of parents for children with SBPs e.g., } \\
\text { http://www.fundacionadana.org/publicaciones/libro) }\end{array}$ & Not reported & $\begin{array}{l}\text { Serrano I.; } \\
\text { Russell Barkley }\end{array}$ \\
\hline
\end{tabular}

Note. 'Not reported' indicates that the expert did not provide an answer. Information in the tables has been presented as reported by experts. 


\section{Appendix B. Authors details}

Alexandra-Raluca Gatej started working as a student research assistant at Curium-LUMC, Centre for Child and Youth Psychiatry in November 2015. She completed the MSc Child \& Adolescent Psychology program, at Leiden University in August 2016, and has since been continuing her collaboration with Curium-LUMC as a $\mathrm{PhD}$ student through a part-time route. She is also currently completing the MSc in Applied Psychology for Children and Young People at University of Edinburgh, Scotland, working within a Child and Adolescent Mental Health Service in Glasgow, United Kingdom.

Audri Lamers is a qualified clinical psychologist and senior researcher. In 2016, she successfully defended her PhD thesis on the parent-team therapeutic alliance in child psychiatry. During the development of this project, Audri worked as a clinical psychologist and senior researcher at Curium-LUMC. Currently she works in De Opvoedpoli Child and Youth Psychiatry and continues combining clinical work and scientific research with a special interest in the application of scientific research results to improve the quality of clinical work.

Lieke van Domburgh is director of quality of care and innovation at Pluryn-Intermetzo, a multi-site center for multiproblem youth and adults both with and without co-morbid mental and physical disabilities, and senior researcher in child and adolescent psychiatry at VU University Medical Center Amsterdam (VUMC). She obtained her doctorate on the development of children under 12 who have been in contact with the police. Her expertise lies within the field of children and young people with serious behavioural problems in (judicial) youth care and cultural diversity.

Matty Crone is an associate professor within the prevention and community care field at the department of public health and community care, Leiden University Medical Center (LUMC). She has extensive research experience in the field of youth and is involved in various studies on the prevention of unhealthy lifestyles amongst young people and the identification of psychosocial problems by Youth Health Care and general practitioners.

Terje Ogden is professor at the department of psychology, University of Oslo, research director at the Centre for Studies of Behavioural Problems and Innovative Practice, The Centre for

Behavioural Research - Unirand, and director of research at the Norwegian Centre for Child Behavioural Development. His research expertise lies within the domain of children behavioural problems, positive behaviour in schools and parent training programs. He is editor in several international journals, including Journal of Emotional and Behavioural Difficulties and Journal of Prevention Science.

Daniel Rijo is associate professor at the Cognitive and Behavioral Centre for Research and Intervention and Faculty of Psychology and Education Sciences, University of Coimbra, Portugal. He obtained his doctorate in clinical psychology at the University of Coimbra. Daniel published numerous scientific articles, books and chapters on topics such as psychopathy, antisocial behaviour, and mental health services in legal institutions.
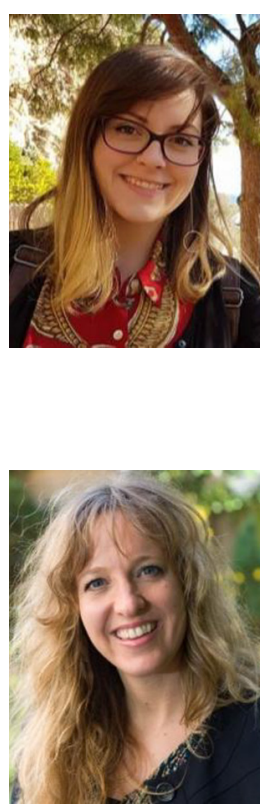

Eeva Aronen is a qualified child psychiatrist, MD, $\mathrm{PhD}$, and professor of child psychiatry at Helsinki University. Her affiliations are at Helsink University, Helsinki University Hospital, and Helsinki Pediatric Research Center, Laboratory of Developmental Psychopathology. The main focus of Eeva's scientific research is on sleep and executive functions in children, the protective and risk factors affecting a child's development, behavioral disorders in children and their treatment.

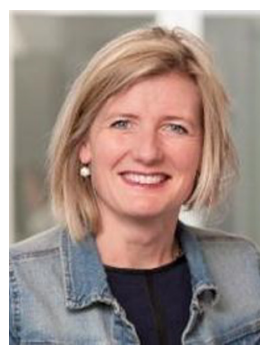

Ricardo Barroso is a qualified clinical and forensic psychologist, and PhD. He works as an assistant professor at the University of Trás-os-Montes and Alto Douro (Portugal), and senior researcher at the research laboratory in human sexuality (SexLab), University of Porto, which focuses on sexual aggression and atypical interests. Ricardo is also offering consultancy in various national and international governmental organizations and has been a member of the Board of the European Association for Forensic Child \& Adolescent Psychiatry and Psychology (EFCAP).
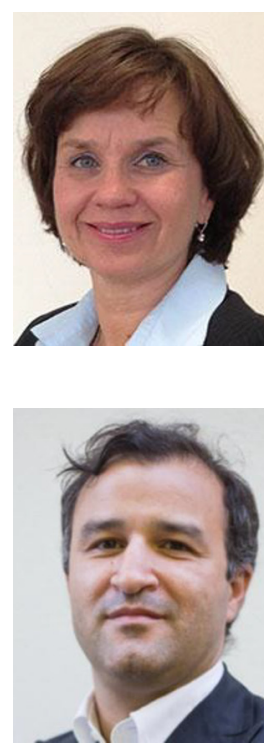

Dorret I. Boomsma is a professor in the department of biological psychology, VU University Amsterdam, and a leading scientist in twin and genetic studies of behavior, health and psychopathology. Dorret has numerous scientific publications on topics such as ADHD in children and behavioural problems in children, with a focus on epigenetics. She is also the coordinator of the ACTION consortium on pediatric aggression, which this project is branching from.

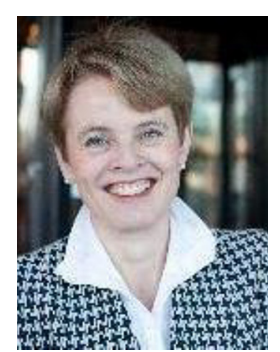

Robert Vermeiren is a qualified child and adolescent psychiatrist. He currently works as a professor of child and adolescent psychiatry at Leiden University Medical Centre, director of patient care of the child psychiatric clinic Curium-LUMC and head of research in De JuttersLucertis Parnassia Group for child and adolescent psychiatry. He is also professor of forensic child and youth psychiatry at the VU University Medical Center Amsterdam. Within the ACTION consortium, Robert is the leader of this project.

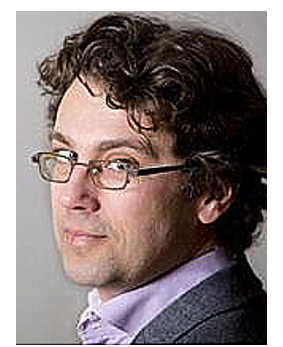

\section{References}

[1] Whaley AL, Davis KE. Cultural competence and evidence-based practice in mental health services. Am Psychol 2007;62(6)563-74. . [Internet] Available from: http://www.ncbi.nlm.nih.gov/pubmed/17874897.

[2] Eibling D, Fried M, Blitzer A, Postma G. Commentary on the role of expert opinion in developing evidence-based guidelines. Laryngoscope 2014;124 (2):355-7.

[3] National Institute for Health and Clinical Excellence. Antisocial behaviour and conduct disorders in children and young people: recognition, intervention and management. Nice Clin Guideline 2013 nice.org.uk/guidance/cg158. 
[4] Francke AL, Smit MC, de Veer AJE, Mistiaen P. Factors influencing the implementation of clinical guidelines for health care professionals: a systematic meta-review. BMC Med Inform Decis Mak 2008;8(1)38, doi:http:// dx.doi.org/10.1186/1472-6947-8-38 [Internet] Available from:

[5] Koivusalo M, Labonte R, Wibulpolprasert S, Kancahanchitra C. Globalization and national policy space for health and a HiAP approach. In: Leppo K, Ollila E, Pena S, Wismar M, Cook S, editors. Health in all policies seizing opportunities, implementing policies. Helsinki: Ministry of Social Affairs and Health; 2013. p. 81-103.

[6] Matthys W. Gedragsstoornissenbijkinderen: diagnostiekenbehandelingvoor de professional. Amsterdam: Hogrefeuitgevers; 2011.

[7] Dodge KA, Coie JD, Lynam D. Aggression and antisocial behaviour in youth. In: Eisenberg En N, Damon W, Lerner RM, editors. Handb child psychol soc emot personal dev. 2006;3:. p. 719-88.

[8] Quy K, Stringaris A. Oppositional defiant disorder. IACAPAP Textb child Adolesc Ment Heal; 2012. p. 1-14.

[9] Lahey BB, Waldman ID. Annual research review: phenotypic and causal structure of conduct disorder in the broader context of prevalent forms of psychopathology. J Child Psychol Psychiatry 2012;53:536-57.

[10] Chacko A, Jensen SA, Lowry LS, Cornwell M, Chimklis A, Chan E, et al Engagement in behavioral parent training: review of the literature and implications for practice. Clin Child Fam Psychol Rev 2016;19(3): 204-15.

[11] American Psychiatric Association, Of M, Disorders M. Diagnostic and statistical manual of mental disorders: DSM-5. [Internet]. Arlington. 2013. . Available from: https://www.sciencetheearth.com/uploads/2/4/6/5/24658156/dsm-vmanual_pg490.pdf.

[12] World Health Organization. The ICD-10 classification of mental and behavioural disorders. Int J Nurs Terminol Classif 1992;10:1-267.

[13] Goodman R, Scott S. Child, Adolescent Psychiatry. Child and adolescent psychiatry: third edition. [Internet] Available from:. third edition 2012. https://www.scopus.com/inward/record.uri?eid=2-s2.084891583953\&doi=10.1002\%2F9781118340899\&partnerID=40\&md5 = fa298f6e9c3db869203fb14bb6d44557.

[14] Johnstone L. Psychological formulation as an alternative to psychiatric diagnosis. J Humanist Psychol. 2018;49(10):887-97, doi:http://dx.doi.org/ $10.1177 / 0004867415600891$.

[15] Vanheule S. Psychiatric diagnosis revisited: DSM to clinical, case formulation. 2017.

[16] Carr A. The handbook of child and adolescent clinical psychology: a contextual approach. [internet] 1-1043 p. Available from:. third edition 2015. https://www.scopus.com/inward/record.uri?eid=2-s2.0-84961193396\&doi= 10.4324\%2F9781315744230\&partnerID=40\&md5= 6b662120b149713b8a866251a2b84a77.

[17] Smith E, Koerting J, Latter S, Knowles MM, Mccann DC, Thompson M, et al Overcoming barriers to effective early parenting interventions for attentiondeficit hyperactivity disorder (ADHD): parent and practitioner views. Child Care Health Dev 2015;41(1):93-102.

[18] Baker S, Sanders MR, Turner KMT, Morawska A. A randomized controlled trial evaluating a low-intensity interactive online parenting intervention, Triple $\mathrm{P}$ Online Brief, with parents of children with early onset conduct problems. Behav Res Ther 2017;91:78-90, doi:http://dx.doi.org/10.1016/j. brat.2017.01.016 [Internet] Available from:

[19] Institute of Medicine (US). Committee on standards for developing trustworthy clinical practice guidelines. Clinical practice guidelines we can trust. Clinical practice guidelines we can trust.. 2011.

[20] Forsner T, Hansson J, Brommels M, Wistedt AA, Forsell Y. Implementing clinical guidelines in psychiatry: a qualitative study of perceived facilitators and barriers. BMC Psychiatry 2010;10:8. . [Internet] Available from: http://www. ncbi.nlm.nih.gov/pubmed/20089141\%5Cnhttp://www.pubmedcentral.nih. gov/articlerender.fcgi?artid=PMC2822755.

[21] Kung J, Miller RR, Mackowiak PA. Failure of clinical practice guidelines to meet Institute of Medicine Standards: two more decades of little, if any, progress. Arch Intern Med 2012;172(21):1628-33.

[22] Scott IA, Guyatt GH. Suggestions for improving guideline utility and trustworthiness. Evid Based Med 2014;19:41-6.

[23] Wolf JS, Hubbard H, Faraday MM, Forrest JB. Clinical practice guidelines to inform evidence-based clinical practice. World J Urol 2011;29:303-9.

[24] Webster-Stratton C, Reid J. The incredible years parents, teachers, and children training series: a multifaceted treatment approach for young children with conduct problems. Evidence-based psychotherapies for children and adolescents.. . p. 194-210.

[25] Sanders MR. Triple P-positive parenting program: towards an empirically validated multilevel parenting and family support strategy for the prevention of behavior and emotional problems in children. Clin Child Fam Psychol Rev 1999;2(2):71-90.

[26] Mittnacht AM, Bulik CM. Best nutrition counseling practices for the treatment of anorexia nervosa: a Delphi study. Int J Eat Disord 2015:48(1):111-22.

[27] Jorm AF. Using the Delphi expert consensus method in mental health research. Aust N Z J Psychiatry 2015;49(10):887-97, doi:http://dx.doi.org/10.1177/ 0004867415600891.

[28] Ross AM, Kelly CM, Jorm AF. Re-development of mental health first aid guidelines for suicidal ideation and behaviour: a delphi study. BMC Psychiatry 2014;14(1):241-51, doi:http://dx.doi.org/10.1186/s12888-014-0241-8.

[29] Kloser M. Identifying a core set of science teaching practices: a Delphi expert panel approach. J Res Sci Teach 2014;51(9):1185-217, doi:http://dx.doi.org/ 10.1002/tea.21171.

[30] Harper M, Cole P. Member checking: can benefits be gained similar to group therapy? Qual Rep 2012;17(2)510-7. . [Internet] Available from: http://www. nova.edu/ssss/QR/QR17-2/harper.pdf.

[31] Maguire M, Delahunt B. Doing a thematic analysis: a practical, step-by-Step guide for learning and teaching scholars *. All Irel J Teach Learn High Educ 2017;9(3)3351-33514 available from: http://ojs.aishe.org/index.php/aishe-j/ article/view/335/553.

[32] Braun V, Clarke V. Using thematic analysis. Qual Res Psychol 2006;3(2): 77-101.

[33] Huijg JM, Gebhardt WA, Crone MR, Dusseldorp E, Presseau J. Discriminant content validity of a theoretical domains framework questionnaire for use in implementation research. Implement Sci 2014;9(1).

[34] Birks M, Mills J. Grounded Theory a practical guide. sage publications; 2015.

[35] Saunders B, Sim J, Kingstone T, Baker S, Waterfield J, Bartlam B, et al. Saturation in qualitative research: exploring its conceptualization and operationalization. Qual Quant 2018;52(4):1893-907, doi:http://dx.doi.org/10.1007/s11135-0170574-8.

[36] Gagliardi AR, Brouwers MC. Do guidelines offer implementation advice to target users? A systematic review of guideline applicability. BMJ Open 2015;5:

[37] Pronovost PJ. Enhancing physicians' use of clinical guidelines. JAMA 2013;E1:. . [Internet] Available from: http://www.ncbi.nlm.nih.gov/pubmed/24310916.

[38] Winther J, Carlsson A, Vance A. A pilot study of a school-based prevention and early intervention program to reduce oppositional defiant disorder/conduct disorder. Early Interv Psychiatry 2014;8(2):181-9.

[39] Joshi PT. Mental health services for children and adolescents: challenges and opportunities. JAMA Psychiatry 2014;71(1):17-8.

[40] Park AL, Chorpita BF, Regan J, Weisz JR. The Research Network on Youth Mental Health. Integrity of Evidence-Based Practice: Are Providers Modifying Practice Content or Practice Sequencing? Adm Policy Ment Heal Ment Heal Serv Res 2015;42(2):186-96.

[41] Schoenwald SK, Kelleher K, Weisz JR, Chorpita B, Gibbons R, Glisson C, et al. Building bridges to evidence-based practice: the MacArthur foundation child system and treatment enhancement projects (child STEPs). Adm Policy Ment Heal Ment Heal Serv Res 2008;35(1-2):66-72.

[42] Saraceno B, van Ommeren M, Batniji R, Cohen A, Gureje O, Mahoney J, et al. Barriers to improvement of mental health services in low-income and middleincome countries. Lancet 2007;370:1164-74.

[43] The AGREE Collaboration. Development and validation of an international appraisal instrument for assessing the quality of clinical practice guidelines: the AGREE project. Qual Saf Health Care 2003;12(1)18-23. . [Internet] Available from: http://www.pubmedcentral.nih.gov/articlerender.fcgi? artid=1743672\&tool=pmcentrez\&rendertype=abstract.

[44] Taylor E, Döpfner M, Sergeant J. European clinical guidelines for hyperkinetic disorder-first upgrade. Eur Child 2004;13(1)i7-30. . [Internet] Available from: http://link.springer.com/article/10.1007/s00787-004-1002-x.

[45] Burke JD, Loeber R. The effectiveness of the stop now and plan (SNAP) program for boys at risk for violence and delinquency. Prev Sci 2014;16(2):242-53.

[46] Eisenberg JM. Globalize the evidence, localize the decision: evidence-based medicine and international diversity. Health Aff 2002;21(3):166-8.

[47] Pijper J, de Wied M, van Rijn S, van Goozen S, Swaab H, Meeus W. Executive attention and empathy-related responses in boys with oppositional defiant disorder or conduct disorder, with and without comorbid anxiety disorder. Child Psychiatry Hum Dev 2018;1-10.

[48] Schoorl J, Van Rijn S, De Wied M, Van Goozen SHM, Swaab H. Variability in emotional/behavioral problems in boys with oppositional defiant disorder or conduct disorder: the role of arousal. Eur Child Adolesc Psychiatry 2016;25 (8):821-30.

[49] Connor DF, Steeber J, McBurnett K. A review of attention-deficit/hyperactivity disorder complicated by symptoms of oppositional defiant disorder or conduct disorder. J Dev Behav Pediatr 2010;31(5)427-40. . [Internet] Available from: http://www.ncbi.nlm.nih.gov/pubmed/20535081. 